\title{
Technology of Project Activity and Modern Language Education
}

\author{
Marina L. Ivleva ${ }^{1, *}$ Nonna L. Bagramyants ${ }^{2, a}$ Vitaly Yu. Ivlev²,b \\ ${ }^{1}$ Peoples' Friendship University of Russia, 6, Miklukho-Maklaya str., Moscow 117198, Russia \\ ${ }^{2}$ National Research University, Bauman Moscow State Technical University (BMSTU), 5/1, 2 d Baumanskaya \\ str., Moscow 105005, Russia \\ ${ }^{a}$ Email: nonnalev@yandex.ru \\ ${ }^{b}$ Email: vitalijivlev@yandex.ru \\ *Corresponding author. Email: marinanonna@yandex.ru
}

\begin{abstract}
The article aims to analyse the possibilities of using in the educational process the actively developed and implemented technology of project activities having language training of future specialists in Russian universities as the example. In this regard, the modern directions of university training are explored from the point of view of their effectiveness. The article also considers the theoretical and methodological principles as the basis of these directions. A brief description of the method of project activity is presented, the most common classifications of various types of this method are given, the features of its application in language education are highlighted, as well as the factors that determine the effectiveness of this method in terms of overcoming the contradictions of the educational process to achieve maximum results in the process of forming language competencies and personal development of students.
\end{abstract}

Keywords: Technology, Project activity, Language education, Interconnection, Traditional and active learning, Methodological principles.

\section{INTRODUCTION}

The modern system of university education in Russia has as its main goal the training of a professionally mobile and stable specialist in the labor market. The profile of a modern specialist includes general competencies, which, in combination with special ones, contribute to the professional and personal growth of a university graduate, give him the opportunity to integrate the acquired knowledge and skills into practice. If we talk about the most actively developing areas of modern education, they are united by the implementation of the principles of scientific character, integrated pedagogical approach (upbringing, education, development), humanism and civic consciousness. The opportunity to combine these areas will serve as a guarantee of the

*Fund: The study was carried out with the financial support of the Russian Foundation for Basic Research in the framework of the research project № 20-013-00477 «An innovative environment for the development of gifted students of a technical university in the context of digitalization». success of the formation of key professional competencies and the socio-psychological development of future specialists.

The emerging radical restructuring of the system of training specialists concerns, first of all, a change in the philosophy of education, a revision of its goals in the direction of a practical orientation and, as a result, a change in the very organization of the educational process in the university in terms of its consistency, integration, innovation, interactivity and humanization. In this context, the technology of project activity is of interest as one of the most actively promoted methods of language training in the educational process.

Recent attempts to rationalize the study and comprehension of the current theory and practice of university education make it possible to single out some areas of educational activity, which, taken together, create a model of its current state.

The system of higher education in Russia has significant theoretical and technological potential. 
At the moment, the subject of concern for theorists and practitioners is the issue of adapting existing educational technologies to the changed realities and social needs. The implementation of a new personality-oriented and communicative approach in higher education can be realised by combining the already known directions of modern education with the elements of optimal pedagogical communication.

\section{ANALYSIS OF THE EFFECTIVENESS OF THE MAIN DIRECTIONS OF RUSSIAN SYSTEM OF HIGHER EDUCATION}

The existing areas of education are represented by 2 groups of approaches to educational technologies: 1) traditional, which gives information and transfers knowledge; 2) active, interpretive learning.

If we do not consider the specifics and details of each of the large groups listed above, we can characterise the principles they profess as follows. For the first approach, it is important: a) a clear delineation of the subject, it is separated from others; b) maximum detailed explanation of the material; c) the student is assessed according to a certain set of standards; d) the teacher's task is to evaluate, guide and lead; e) focus on overcoming difficulties in mastering the discipline. The second approach includes a list of the following features: a) knowledge is the ability to organize thought, interpret facts and act according to a decision made; b) the nature of the student is characterised by an interest in acquiring knowledge and an intrinsic desire to explore the world around him; c) the maximum degree of the student's creative independence; d) the teacher's task is to organise a dialogue, during which students test their knowledge and learn to use it; e) even at the initial stage, the student already knows a lot about the subject and can transfer his experience to the studied discipline [1], [2].

The analysis of modern trends does not allow us to give an unambiguous answer about the most effective technologies used. Each teacher makes an individual decision which of the approaches to use in work to achieve the maximum result, depending on: a) the individual psychological characteristics of the teacher and students; b) the level of education; c) learning situations [3].
There are studies (M.K.Kabardov, [4]), which proved the high efficiency of traditional teaching methods while working with students - the socalled "thinkers", who are characterized by the analytical type of intellectual activity: it is easier for them to learn the material presented in the traditional way than the material, which the teacher rendered by using active methods and techniques.

The example of the school «Waldorf of the Peninsula», located in Silicon Valley (USA), where the children of IT giants (Google, Apple, Yahoo, Hewlett-Packard, eBay) study, is very indicative. The school is equipped with somewhat oldfashioned teaching aids (chalk, bookshelves, encyclopedias, wooden desks, notebooks, pens, pencils) in the complete absence of tablets or laptops. The teachers of the school try to solve complex problems of forming a modern personality by developing creative thinking, human relationships, attentiveness, mobility, coordination of children, their ability to structure information, synchronize body and brain. "Education is primarily about human emotional experience, gaining knowledge of life," says Paul Thomas, a former teacher and professor at Furman University, who has written 12 books on educational practices in US government institutions. He argues that technology is only a distraction when a teacher needs to teach literacy, numeracy and critical thinking, which can be shaped using time-tested traditional methods. [5]

Thus, the conclusion about which of the directions is more effective is not based on an assessment of individual characteristics of each of the approaches considered, but rather on the possibility of using it to achieve the main goal of education - the positive development of the student's professionalism with a focus on personally significant areas of his self-education [6], which is facilitated by such an education system, which forms students' ability to acquire knowledge by themselves.

\section{LANGUAGE EDUCATION AS AN ELEMENT OF THE HUMANITIES EDUCATION SYSTEM}

Today's system of humanities education is developing within three clearly defined trends: 1) a change in the educational paradigm from the socalled "knowledge-ability-skill" to the competence paradigm; 2) updating the content of humanitarian disciplines taught; 3) working out methodological 
support for the educational process of training specialists.

A foreign language is included in the compulsory block of humanitarian disciplines. This subject is both the goal of educational impact and the form of its implementation. At the same time, a foreign language course, within the framework of general professional training, performs an instrumental and service function. On the one hand, a foreign language serves as a setting for introducing the content of specialized disciplines and helps to get acquainted with the world scientific and practical experience. In addition, it is necessary to mention the importance of the subject in the personal, psychological and intellectual development of students: the formation of a picture of the world of a different society, the development of communication skills, elimination of psychological barriers, operating with a different system of signs, the development of the ability to analyze and synthesize, the expansion of working memory, language guess, logical thinking, decision making, leadership development, etc. It is thanks to the multitasking of the foreign language course that it seeks to bring together and use already existing and new educational techniques and technologies to the maximum extent.

With regard to the foreign language course, which is most affected by the ongoing reforms, there is a situation of active theoretical and practical search. Theorists and practitioners of language education are trying to implement the solutions for the formation of a modern selfdeveloping personality, capable of coping with as many professional challenges as possible by organizing certain conditions for teaching a foreign language.

One of the possible ways to achieve the stated goals is to use the project methodology, which will stimulate students to maximize their intellectual potential and develop communicative competencies. It is important to emphasize that this approach combines both traditional and new, interactive techniques and teaching methods and allows students to feel like real participants in various situations of professional activity.

\section{TECHNOLOGY OF PROJECT ACTIVITY IN LANGUAGE EDUCATION}

The project method is a system of educational and cognitive techniques aimed at solving a certain problem as a result of the student's independent work with the obligatory presentation of the results of their actions.

The technology of project activity originates in humanistic psychology, D. Dewey is considered to be its author [7]. His pragmatic pedagogy laid the foundations for a new didactic system that took into account the interests of children and was based on the principles of cooperation between the participants in the pedagogical process, their free creativity through activities and overcoming difficulties. D. Dewey's student W.H. Kilpatrick [8] developed the ideas of his teacher and created a school in which students tried to find a way out of life situations, thereby acquiring invaluable life experience and knowledge, and W.H. Kilpatrick denied the need to systematize the applied technology in the form of some kind of curriculum.

The project methodology today is one of the most actively developed in pedagogical theory and practice. As a subject of scientific research, it is studied in detail in the works of many foreign and Russian methodologists: I.L. Beam, I.A. Zimnyaya, T.E. Sakharova, O.M. Moiseeva, E.S. Polat, I. Chechel, A.S. Sidenko. A.G. Rappoport, L. FriedBooth, T. Hutchinson, D. Phillips, A.A. Verbitsky and others.

There are many classifications of the project method (A.S. Sidenko [9], A.G. Rappoport [10], E.S. Polat [11], etc.). The following types of projects, which have different bases, can be listed:

- $\quad$ subject, inter-subject and system projects are distinguished considering their subjectcontent area;

- research, informational (collection of materials) and applied (with a specific product of activity in the form of a script, creating a blog, a project to modernize the office, etc.) projects, which differ in the nature of the activities of the authors of the project;

- group, general course, faculty, regional, international, etc. (methods are classified according to the scale of application).

The introduction of the project methodology into the practice of language education requires compliance with the following methodological principles of the teacher's work:

- training should be based on the principle of maximum identification and development of the individual characteristics of the 
student through stimulating initiative and independence in their cognitive activity;

- teachers use communicative, active, personality-oriented and socio-cultural approaches, adhere to general methodological principles while observing specific principles of language teaching, such as maximum objectivity of information, the connection between the research conducted by students and the real situation, which contributes to the combination of academic knowledge and practical actions, the use of comparative approach in the study of modern realities, interactivity between students and a teacher, systematization, complexity, problem solving, visual support;

- the implementation of the project methodology is based on the predictable profile of students, their individuality is taken into account (interests, topics, level of training, psychological characteristics, the ability to independently obtain information, etc.); the methods and techniques used are founded on the latest achievements in psychology, pedagogy, methodology and didactics, philosophy and other humanitarian disciplines; students are offered freedom of choice in determining the topic, partners, research methods, and the form of presenting the results; practical tasks that are carried out within the framework of the methodology are aimed, among other things, at self-education of language learners.

- the content value of the materials included in the studied discipline is determined by their authenticity, modernity for students, they have practical, cognitive and personal significance for the target audience; on the other hand, the project being carried out should be a difficult goal, the achievement of which will lead to an increase in the cognitive activity of students.

An equally important factor that determines the effectiveness of the methodology of project activities is the relationship between the participants in the educational process. Today's philosophy of language learning presupposes an equal partnership between the learner and the educator. In the traditional model, the main reference point was the teacher as a source of knowledge, and knowledge itself was an end in itself. In modern society, knowledge becomes a condition for the successful realization of an individual, of his professional activity. The project methodology is based on a model of pedagogical activity focused on the learner, whose initiative acts as the driving force of learning. An emotional component is added to learning, which makes the process of acquiring knowledge more productive.

The teacher's position is changing radically. $\mathrm{He}$ becomes the organizer of the activity of studying, searching, analysing and processing information. The gradual transfer to the student of the function of managing and regulating his own educational work within the framework of the project methodology does not mean that the teacher leaves the pedagogical scene or that his role diminishes. In a sense, his activity becomes more complex, creative, requiring more concentration and effort. That is why the methodological skill of the teacher is very important, together with his mastery of the general methodological technics, while observing the basic methodological principles of language training, which largely contributes to the teacher's creative self-realization.

The project methodology is valuable because it allows the teacher and students to carefully develop and think over all stages of the preparation and implementation of a project in a foreign language. The very project activity is preceded by the identification of the problem, which is subsequently formulated in the form of a hypothesis. At this preparatory stage, a certain list of research actions is planned and developed, their plan is drawn up, roles are assigned, the form of presentation of results is determined, terms, materials and sources are established. The stage of the project activity itself involves the collection of data, their analysis, making some conclusions, which are checked and corrected, a presentation is prepared, and, if necessary, the technical side of the project is also thought out. At the last stage, the project is presented to the audience, but summing up the results includes discussion and speeches of opponents with a reasoned assessment, introducing the corrections, rethinking the conclusions and writing a report.

The application of the project methodology in the process of language training allows to successfully overcome the contradictions existing today in the educational process.

The resolution of the contradiction in the content area, which manifests itself in the discrepancy between the needs of society and the result of higher education, is possible through a project methodology: the development of productive thinking of future specialists will ensure their readiness to independently and creatively 
respond to the emerging challenges of the time, which fully meets the current realities of educational practice.

Overcoming the organizational difficulties of the system of university language training is associated, first of all, with the traditional perception of the student as an object of study. The methodology of project-based teaching can be one of the most effective ways to overcome the aforementioned contradiction, since it is personality-oriented in nature, presupposes the maximum consideration of the interests, needs and personal characteristics of the students. The student acts as an equal participant in the learning process. The process itself is based on the principles of interaction and conscious partnership between the student and the teacher. At the same time, the independence of students develops, they feel personal responsibility for the effectiveness of training. This means making a decision on the subject of projects, methods and ways of its implementation, finding material for independent work and additional materials that are of professional and research interest. In this sense, one of the positive results of using projects is overcoming the infantilism of students, their unwillingness to take responsibility for the direction of their professional and personal development.

One more problem area can be identified - the declining level of interdisciplinary connections. It has been proven that interdisciplinarity and integration are essential components of the project method in language teaching: the student possesses a certain set of subject knowledge and competencies from other areas of special training, which must necessarily be integrated when performing a project in a foreign language.

The advantages of the project methodology in the practice of language training include the fact that it acts as an ideal educational field for combining already known areas of modern education with the elements of innovative technologies (problem learning, situationally conditioned learning, game technologies, debate method, modular learning technology, interactive training, scenario-contextual technique, etc.).

The project method also helps to overcome methodological difficulties, namely, to meet the needs of students who demonstrate an exclusively pragmatic approach to acquiring narrow professional competencies: a project is an opportunity for a student to evaluate the practical benefits of the formed competencies, to increase his interest through the development of internal motivation, to recreate situations of real professional behavior, which has a high personal meaning for the learner.

\section{CONCLUSION}

The project methodology acts as a powerful means of achieving the goals and objectives of the development of students, creates opportunities for realizing their personal potential, intensifies their intellectual activity, and makes students more independent in acquiring knowledge, since their responsibility for the acquired competencies increases.

In the era of multiculturalism and globalization in modern linguodidactics and methodology, there is a shift in emphasis towards integrative research. One such practice is the project method. It has many advantages and is the best way to empirically test theoretical knowledge. Practice has shown that its application in the system of language education contributes to the maximum immersion of students in real life and professional situations, helps to form the student's ability to act, to solve professional and personally significant tasks and to demonstrate the practical benefits of the acquired competencies.

\section{AUTHORS' CONTRIBUTIONS}

Marina Ivleva: Made a significant contribution to the collection, analysis and interpretation of data; Participated in editing a draft version of the article; Approved the final version of the article for publication; Agreed to be responsible for all aspects of the study that may raise questions related to its accuracy, integrity and credibility.

Nonna Bagramyants: Made a significant contribution to the design and development of the study design; Participated in writing a draft version of the article; Approved the final version of the article for publication; Agreed to be responsible for all aspects of the study that may raise questions related to its accuracy, integrity and credibility.

Vitaly Ivlev: Made a significant contribution to the collection, analysis and interpretation of data; Participated in editing a draft version of the article; Approved the final version of the article for publication; Agreed to be responsible for all aspects of the study that may raise questions related to its accuracy, integrity and credibility. 


\section{REFERENCES}

[1] D. Barnes. From communication to curriculum. Portsmouth, NH: Boynton/CookHeinemann, 1992. 81 p.

[2] M.L. Ivleva, N.L. Bagramyants, V. Yu.Ivlev. Discussion on some features of innovative system of professional training (ICELAIC 2018) // Proceedings of the 5th International Conference on Education, Language, Art and Inter-cultural Communication. Advances in Social Science, Education and Humanities Research, vol. 289, pp.14 - 19.

[3] M.L. Ivleva. Educational technologies in work with gifted students // Proceedings of 4th International Conference on Education, Language, Art and Intercultural Communication (ICELAIC 2017) Part of the series ASSEHR, Moscow, Russia, pp. 73 -77.

[4] M.K. Kabardov. Language abilities: psychology, psychophysiology, pedagogy. Moscow: Publishing House "Smysl", 2013. $400 \mathrm{p}$.

[5] adme.ru [Electronic Publication]. URL: http://www.adme.ru.

[6] V.V. Safonova. Co-study of Russian and English languages in the context of the dialogue of modern civilizations // "Russian language in the changing world. International scientific and practical conference. April 14, 2006, Moscow, pp. 9-26.

[7] J. Dewey. Democracy and education: Translated from English / John Dewey. Moscow: Pedagogika-Press, 2000. 384 p.

[8] W.H. Kilpatrick. The Project method. Application of the target setting in the pedagogical process. L., 1925. $52 \mathrm{p}$.

[9] A.S. Sidenko. Project method: history and practice of application //Head teacher. 2003, No. 6, P. 96 - 112.

[10] A.G. Rappoport. Design boundaries // Questions of methodology, 1991, No. 1, pp. $26-30$.

[11] E.S. Polat. New pedagogical and information technologies in the education system. Moscow: Publishing Center "Academy", 2003. $272 \mathrm{p}$. 